\title{
Erratum
}

Journal of Earth System Science

Volume 120, Number 1, February 2011, pp. 123-144

\section{Sand and clay mineralogy of sal forest soils of the Doon Siwalik Himalayas}

\author{
Mukesh, R K Manhas, A K Tripathi, A K Raina, \\ M K Gupta and S K KamboJ
}

Due to an oversight, table 7 (pp. 140-141) of the article was wrongly printed in the February 2011 issue. The correct table 7 is given overleaf. The Web version of the original article (http://www.ias.ac.in/ jess/feb2011/123.pdf ) contains the correct table. 


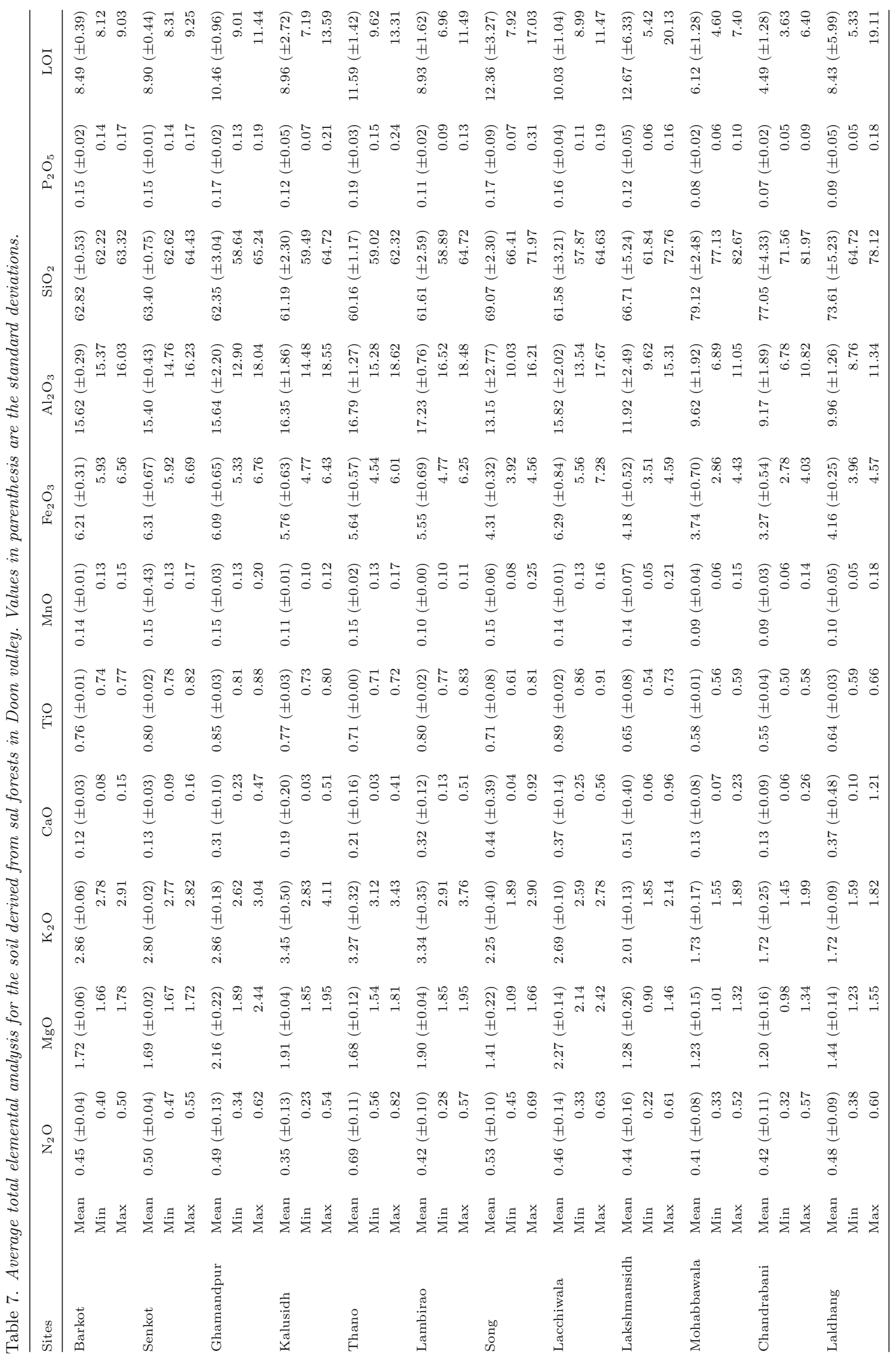

